\title{
Diet and Nutrition: Metabolic Diseases
}

\author{
Gundu HR Rao* \\ Heart Institute, University of Minnesota, USA
}

*Corresponding author: Gundu HR Rao, 12500 Park Potomac Ave Unit 306N, Potomac MD 20854, Lillehei Heart Institute, University of Minnesota, USA .

Received Date: August 08, 2018

Published Date: August 28, 2018

\begin{abstract}
"You Are What You Eat; how to win and keep health with diet", was the title of a book, that nutritionist Victor Lindlahr wrote in 1920s. Since then, several nutritionists have written extensively on this topic. Over the years, scientists, clinicians, policy makers, and professional societies, have offered contradictory advice of what to eat or what not to eat, and when to eat. In view of the fact, that my interests are focused on metabolic diseases, I will start this essay with some introduction to metabolism, as it modulates the activities at molecular, cellular, organ, and total body level. In brief, metabolism is the chemical process your body uses, to transform the food you eat into the fuel, that keeps you alive and well. Diet and nutrition by and large, consists of proteins, carbohydrates, fats and a variety of micronutrients. These substance's when ingested are broken down by enzymes in our digestive system, and then carried to the cells, where they can be used as fuel. The body either uses these metabolites immediately, or stores them in the liver, body fat, and muscles for later use. A metabolic disorder occurs, when the metabolic process fails and causes body to have either too much or too little of the essential metabolites needed to stay healthy. In the ancient science of Ayurveda, the Indian Traditional Medicine, alterations in metabolism are called "doshas", meaning metabolic defects. In the holistic approach, attempts are made to keep these dos has in a perfect balance, so that the risks for various diseases are not developed. All the known metabolic diseases, such as hypertension, excess weight, endothelial dysfunction, subclinical atherosclerosis, obesity, metabolic syndrome, and type-2 diabetes, have reached epidemic proportions worldwide. In this overview, we will discuss some of the known metabolic alterations that promote the risks for developing metabolic diseases and present our views on the subject. .
\end{abstract}

\section{Introduction}

The metabolic diseases that we are going to discuss, are basically lifestyle diseases. Although genes that one inherits, may influence the development of metabolic diseases, they are of less importance, when compared to the epigenetic factors that influence the development of these diseases. According to the noncommunicable diseases (NCD) task force, obesity has increased by two-fold and type- 2 diabetes by four-fold in the last three decades $[1,2]$. They conclude, that if the rate of increase of these diseases are not controlled, chances of meeting the Millennium Development Goals (MDG) of keeping the level of prevalence of these diseases in 2015 at 2020 is negligible. Countries with huge populations, like India and China have larger share of diabetics than the number of diabetics in the rest of the world. For instance, in China, in the last three decades rate of increase in the incidence of diabetes is 17 -fold. Data from Nurses' Health Study suggests that 90 percent of type- 2 diabetes can be attributed to five risk factors: excess weight, lack of exercise, a less than healthy diet, smoking and alcohol consumption [3]. This is true in general population as well, according to the results of INTERHEART studies done in 52 countries. If we look at the major diet in India and China, it is carbohydrate-rich. Talking about diets, there is convincing evidence, that diets rich in whole grains protect against diabetes, whereas diet rich in refined carbohydrates increase the risk. In the Nurses' Health Studies that we referred earlier, researchers looked at the whole grain consumption of more than 160,000 women, whose health and dietary habits were followed for up to 18 years. Women who averaged three servings of whole grains a day, were $30 \%$ less likely to have developed diabetes, than those who rarely ate whole grains [4]. How about those who are nonvegetarians? There is increased evidence that eating red meat and processed meat, increases the risk for diabetes. The researchers of a seminal, long-term study looked at 440,000 people, about 28,000 of whom, developed diabetes and found that just one serving of 3-ounce red meat, increased risk for diabetes by 20 percent [5]. One of the reasons for the detrimental effect of dietary red meat, seems to be the high iron content, which is supposed to damage 
insulin producing cells and interfere with insulin's effectiveness. Apart from the refined grains and red meat, dietary fats also seem to play a great role in the development of excess weight, Obesity, and diabetes. Good fats in the diet, such as polyunsaturated fatty acids (PUFA) seem to ward off diabetes, whereas trans fats seem to do the opposite. Eating PUFA from fish (Omega-3 fatty acids), though recommended by the American Heart Association, has failed to show any beneficial effect in reducing CVD events [6]. In this overview, we will discuss, modifiable risk factors, less know risk markers, and possible interventions. In a short overview like this, it is hard to cover all aspects of diet and nutrition as related to the development of metabolic risks, readers are urged to refer to original articles, reviews, and monographs [7-18].

\section{Discussion}

Whenever I have been asked to review this topic, I always wonder as to where to begin? Well, let me start with the very beginning, the definition of metabolic alterations. A metabolic disorder occurs, when the metabolic process fails and causes body to have, either too much or too little of the essential metabolites needed to stay healthy. How early is early, when planning preventive strategies? Millions of children are born with low-birth weight worldwide. According to the pioneering ongoing bilateral studies between India and the UK, children with low birth weight, when they grow to adulthood develop excess metabolic diseases. In other words, this cohort is "at risk" for developing metabolic diseases. Once again, before, I proceed further, I want to make it clear that we are not talking here about "metabolic syndrome", a cluster of metabolic risks, but we are discussing metabolic alterations in general, that promote the risks for developing metabolic diseases, such as hypertension, excess weight, obesity, metabolic syndrome, endothelial dysfunction, and subclinical atherosclerosis. Now having explained the theme of this overview, let us get back to the question of how early is early for the detection and intervention of metabolic risk.

The low-birth-weight (LBW) remains a high risk for infant mortality $[19,20]$. Collaborative Studies in India, from Medical Research Council (MRC) of United Kingdom (UK), with Mission Hospital Mysore (MHM), and King Edward Memorial (KEM) Hospital, Pune, have demonstrated that over a third of all babies born in India, are of low-birth-weight (LBW). Follow up of these LBW babies have demonstrated that they develop a significantly high incidence of elevated blood pressure, obesity, diabetes (type2) and cardiovascular diseases (CVDs). In view of these findings, MRC has set up an epidemiology resource center at KEM hospital Pune and at Mission Hospital, Mysore. This is not a finding that is unique to the South Asians [21-28]. Xiao and associates in Beijing, China, studied individuals born between 1921 to 1954 , at the Peking Union Medical College Hospital, to estimate the association between birth weight and Metabolic Syndrome (MS). They defined MS, as per the National Cholesterol Education Program (NCEP) Adult Treatment Panel (ATP111) guidelines [22]. According to their studies, the prevalence of MS was 27\%, though $55 \%$ of the subjects had as least two components of the MS. In the 1980s, Barker developed a hypothesis according to which, many nutritional events that occur during the intrauterine growth, will influence the development of adult diseases [23,25,29]. In spite of the fact that millions of children or born worldwide, who are "at risk" for developing metabolic diseases, no intervention has been developed to prevent this nutritional deficiency of pregnant women and neonates. A meta -analysis on this subject by the researchers at the Harvard School of public health concluded that multiple micronutrient supplementation was more effective, than iron and folic acid supplementation at reducing the risk of low birth weight [30].

Professor Yajnik [31] and associates, have also demonstrated the role of micronutrients in their "Pune Maternal Nutrition Study". These researchers also have shown, that Indian babies have low muscle mass but preserve body fat, which may predispose them to an insulin-resistant state. We are very much interested in exploring, if in addition to the nutrient-deficiency, any other the molecular mechanisms, dictate the metabolism of the growing fetus. In view of the early observations made in this institution, and our renewed interest in this topic, we have initiated a bilateral study between the researchers of the Children's National Memorial Hospital (CNMH), Washington DC and the staff of KEM, Hospital Pune, India, to explore early biomarkers for the fetal origin of adult diseases. Dr. Robert Freishtat and associates at the CNMH, Washington DC, have demonstrated that visceral adipocytes shed exosomal-mediators (microRNAs) predicted to regulate key end-organ inflammatory and fibrotic pathways [31]. Preliminary studies between these two institutions have been encouraging, and we are seeking funding from the prestigious National Institutes of Health (NIH) USA, for further studies on this important topic. What other metabolic alterations can we consider as early markers for metabolic diseases? Researchers of the Framingham Heart Study Group, using highthroughput profiling of blood, have found that five branched-chain and aromatic amino acids had highly-significant associations with future incidence of diabetes: isoleucine, leucine, valine, tyrosine, and phenylalanine [32]. A combination of three amino acids predicted future diabetes ( $>5$-fold higher risk for individuals). According to the authors, "these findings underscore the importance of amino acid metabolism, early in the pathogenesis of diabetes and suggest, that amino acid profiles could aid in diabetes risk assessment". Studies by Chen and associates confirmed these earlier results from the USA in Chinese populations [33]. Kume [34] and associates from Japan, extended these studies to assess whether an indexbased on plasma free amino acids (PFAA), could predict the onset of CVD in diabetic patients [35]. These researchers concluded, that metabolic profiling is useful for identifying diabetic patients at risk for CVD, regardless of the degree of albuminuria, or for improving the discriminative capability of combining with albuminuria.

According to the recent nutritional guidelines, the 1800 calorie American Diabetes Association diet is dead. However, if one uses the standard "calorie calculators", even now the daily calorie recommendation, may show 1800 and over for an average adult. The modern diet for the individual with diabetes, is based on concepts from clinical research, portion control, and individualized lifestyle changes. Leading authorities and professional organizations have concluded that proper nutrition is an important part of the foundation, for the treatment of diabetes. Readers are urged to refer 
to the original guidelines, current revisions, and recommendations for further details [36,37]. Americans on an average consume 250 to 300 grams of carbs a day, accounting to $55 \%$ of their daily intake. All carbohydrates get converted into sugar in the blood, the more refined the carbs are, the quicker the conversion occurs. Studies done in several laboratories, have demonstrated the beneficial effect of Mediterranean and low carb diet, compared to the low -fat diet. In a 12 -week study, Prof. Stephen Phinney (Emeritus Professor of Nutrition, at UC Davis, USA) and his associates put 40 subjects with metabolic syndrome on a 1500-calorie diet. Despite the high fat that the low carb diet group was getting, at the end of the study levels of triglycerides had dropped by $50 \%$ in this group. Levels of good cholesterol (HDL) increased by 15\%. The researchers concluded, that contrary to what one may expect, dietary fat intake was not directly related to blood fat. Rather the amount of carbohydrates in the diet appears to be a potent contributor [38,39].

"Fat is not the problem," says Dr. Walter Willett, Chairman of the Department of Nutrition at the Harvard School of Public Health (LA Times, 2/20/2016). "If Americans could eliminate sugary beverages, potatoes, white bread, pasta, white rice and sugary snacks, we would wipe out almost all the problems we have with excess weight and diabetes and other metabolic diseases." Quite a powerful statement coming from the Chairman of the Nutrition Department of the Harvard School of Public Health. Roy Taylor and associates, at the University of New Castle, UK, have shown that a low-calorie diet (850 Cal diet) caused remission in $90 \%$ of trial patients, who lost $15 \mathrm{Kg}$ or more, even in those who had been diabetic for six years or more [40]. Since carbohydrate is the micronutrient, that raises blood glucose levels most significantly, the greatest debate is how low in carbohydrates the diet should be. This is the logic behind the popularity of the Ketogenic diet, which is a very low-carbohydrate, low protein, high-fat diet [41].

Historically speaking, dietary management of diabetes goes back to centuries. According to a report in the Wikipedia, dietary management of diabetes was used in Egypt since 3500 BC, and in India by Sushruta and Charaka, more than 2000 years ago. Most recent American Heart Association (AHA) diet and lifestyle recommendation (July 27, 2018), lists the overall dietary healthy pattern as follows: a variety of fruits and nuts; whole grains; lowfat dairy products; skinless poultry and non-fried fish; nuts and legumes; non-tropical vegetable oils. One of the seminal studies on the CVD prevention at the population level was the Finnish study, done at North Karelia in Finland [42-44]. According to "Pekka Puska Reports, "Prevention in Action", in 1960s, Finland had the highest rate of deaths from coronary artery disease, especially in the province of North Karelia. In 1971, representatives of the Province signed an appeal to the National Authorities for urgent help to reduce the burden of CVDs in this area. Finnish authorities, with the help of WHO, launched The North Karelia Project: Thirty Years Successfully Preventing Chronic Diseases. At the time of launch several studies including the findings from FHS, had pointed out the likely importance of risk factors such as high LDL- cholesterol high blood pressure and tobacco use.

These studies had demonstrated, the strong influence of diet, especially the quality and quantity of dietary fat, on the levels of blood cholesterol. Smoking was quite common in this population. A high intake of salt, saturated fat, and low intake of vegetables were likely the cause of high blood cholesterol and high blood pressure in this population. The aim of this project was, to change the general risk-related life styles, through community-based actions. Over the 30-year period, there were significant changes in the life style of this population. At the beginning of this project almost all people used butter on their bread and in cooking. Nowadays, according to the report less than $5 \%$ of people use butter on bread and around $60 \%$ of the households, use vegetable oil for cooking. According to Pekka Puska Report, the age-standardized mortality rate for coronary heart disease among men in North Karelia in 2006 was 85\% lower than during the period 1969-71; nationally, the reduction was a whopping $80 \%$. The North Karelia project was the first and one of a kind comprehensive community-based program, to demonstrate a positive impact on CVD death and disability. However, there were several earlier population-based studies, which also had shown observation-based correlation between choice of diet and CVD risks.

In spite of these findings by seminal epidemiological studies, a recent issue of TIME magazine (June 23, 2014) had a cover page, which said: "Eat Butter". Don't Blame Fat, says Bryan Walsh, in a story in the same issue of the magazine. He continues, "For decades, it has been the most vilified nutrient in the American diet. But new science reveals, fat isn't what's hurting our health". Paul John Scott a columnist for a Minnesota News Paper wrote, "How dodgy research with a Minnesota connection, led to the low-fat diet, which turns out, is not just unsustainable but morbidly so". He based much of his arguments on the basis of a book, "The Big Fat Surprise" by Nina Teicholz, another journalist. However, reviewing all the scientific evidence available, I came to a different conclusion than what was expressed by these journalists. Modern medicine is an emerging experimental discipline. As is with all investigational fields, there is nothing like "absolute truth". Based on available evidence, with limitations of course, the guidelines are developed by National and International Professional Societies and Institutions. No journalist can wipe out all the results, that came out of the North Karelia studies [42-44] or the Seven Countries Studies [45,46]. These journalists by suggesting that a high-fat diet would be fine, are making the same mistakes, as others have done earlier. It is very important to remember, that benefits of modifiable risks, have withstood scrutiny better than any individual dietary manipulations. Even if we promote good life style, including, exercise and abstinence of the use of tobacco or tobacco products, results will outweigh the benefits of dietary manipulations. Having said that, I would like to appeal to all the researchers working in the areas of Nutrition and Food Sciences, that there is a great window of opportunity, for developing evidence-based food supplements, that can play an important role as complementary therapies, for the management of metabolic risks and related diseases [47-49].

\section{Conclusion}

A comprehensive discussion on diet, nutrition, lifestyle, diseases, and wellness, are beyond the scope of a short overview like this. Moreover, dietary recommendations are indeed controversial, and many clinical studies also have yielded controversial results. 
Take for example, the fish oil story, after ten randomized clinical trials, the results did not provide the answers, the researchers were looking for, when they planned these studies. In this overview, we have described how good nutrition is important, right from the time of conception, gestation period, as well as for neonatal growth. We have presented results of studies, in which micronutrient deficiency has been shown, to precipitate and promote the fetal origin of adult diseases. We also have discussed preliminary studies, showing altered roles of metabolites (micro RNAs, branched chain amino acids), in promoting the development of metabolic diseases. We have briefly discussed, the role of dietary carbohydrates and fats in the promotion of metabolic diseases. Although very well established, we have not discussed the role of excess salt and sugar consumption, in promoting metabolic diseases. In spite of the wise recommendations of Professor Walter Willet, Chairman of the Nutrition Department, Harvard School of Public Health, it is hard to come up with an acceptable healthy diet for populations worldwide. Even if we did develop such a "healthy diet", it is hard convincing the entire population, to stick to such a diet. Just imagine fighting the food and dairy industry. The choice we have at this time is, to follow the guidelines and guidance statements of various professional societies such as, American Society of Nutrition, American Heart Association, American Diabetes Association, American Obesity Association, and International Union of Food Science and Technology.

\section{References}

1. NCD Risk Factor Collaboration (2017) Worldwide trends in bod-mass index, underweight, overweight, and obesity from 1975-2016: a pooled analysis of 2416 population-based measurement studies in 128.9 million children, adolescent, and adults. Lancet 390 (10113): 2627-2642.

2. NCD Risk Factor Collaboration (2016) Worldwide trends in diabetes since 1980: a pooled analysis of 751 population-based studies with 4.4 million participants. Lancet 387(10027): 1513-1530.

3. Hu FB, Manson JE, Stampfer MJ, Colditz G, Liu S (2001) Diet, lifestyle and the risk of type 2 diabetes mellitus in women. N Engl J Med 345(11): 790-797.

4. de Munter JS, Hu FB, Spiegelman D, Franz M, van Dam RM (2007) Whole grain, bran, and germ intake and risk of type 2 diabetes: a prospective cohort study and systematic review. PLoS Med 4(8): 261.

5. Pan A, Sun Q, Bernstein AM, Schulze MB, Manson JE (2011) Red meat consumption and risk of type 2 diabetes: 3 cohorts of US adults and an updated meta-analysis. Am J Clin Nutr 94(4): 1088-1096.

6. Rao GHR (2018) Omega-3 Fatty Acids: Cardiovascular Disease. J. Cardiol Cardiovasc Ther 10 (5): JOCCT.MS.ID55597.

7. Schulze MB, Hu FB (2004) Dietary approaches to prevent the metabolic syndrome. Diab Care 27 (2): 613-614.

8. Hu FB, Willett WC (2002) Optimal diets for prevention of coronary heart disease. JAMA 288(20): 2569-2578.

9. McKeown NM, Meigs JB, Liu S, Saltzman E, Wilson PW (2004) Carbohydrate nutrition, insulin resistance, and the prevalence of the metabolic syndrome in the Framingham Off spring Cohort. Diabetes Care 27(2): 538-546.
10. Ebrahimof S, Mirmiran P (2013) Nutritional approaches for prevention and treatment of metabolic syndrome in adults. J Paramed Sci 4(2): 123134.

11. Byrne CD, Wild SH (2005) The metabolic syndrome. (2 $2^{\text {nd }}$ edn) WileyBlackwell, USA, p. 384.

12. Cornier MA, Dabelea D, Hernandez TL, Lindstrom RC, Steig AJ, et al. (2008) The metabolic Syndrome. Endocr Rev 29(7): 777-822.

13. Yamaoka K, Tango T (2012) effects of lifestyle modification on metabolic syndrome: a systematic review and meta-analysis. BMC Med 10:138.

14. Beavers KM, Nicklas BJ (2011) Effects of lifestyle interventions on inflammatory markers in the metabolic syndrome. Front Biosci (Schol Ed) 3: 168-177.

15. Lichtenstein AH, Appel LJ, Brands M, Carnethon M, Daniels S, et al. (2006) Diet and lifestyle recommendations revision 2006: a scientific statement from the American Heart Association Nutrition Committee. Circulation 114(1): 82-96.

16. Feldeisen SE, Tucker KL (2007) Nutritional strategies in the prevention and treatment of metabolic syndrome. Appl Physiol Nutr Meta. 32(1): 46-60.

17. Castro-Barquero S, Ruiz-Leon AM, Sadurni M (2017) Dietary strategies for metabolic syndrome: A review. J. Obesity and Ther. 1(2): 1-5, 2017.

18. Estruch R, Ros E, Salas-Salvadó J, Covas MI, Corella D, et al. (2018) Primary prevention of cardiovascular disease with a Mediterranean diet supplemented with extra-virgin oil olive oil or nuts. N Engl J Med 378 (25): 34 .

19. Rao GHR and Bharathi M: Mother and Child: First step for prevention of cardiometabolic diseases. J. Cardiol. (Photon J.) 109:179-186, 2016.

20. McCormick MC (1985) The contribution of low birth weight to infant mortality and childhood morbidity. N Engl J Med 312(2): 82-90.

21. Xinhua Xiao, Zhen-Xin Zhang, Wen-Hui Li, Kai Feng, Qi Sun, et al. (2011) Low birth weight is associated with components of the metabolic syndrome. Metabolism 59(9): 1282-1286.

22. Barker DJP (1998) Mothers, Babies and Health in Later Life. 2nd Edition, Edinburgh, Churchill Livingstone.

23. Carlos Antonio Negrato, Marilia Brito Gomes (2013) Low birth weight: Causes and consequences. Diabetol Metab Syndr 5: 49.

24. Barker DJ (1997) Maternal Nutrition, Fetal Nutrition and Disease in Later Life. Nutrition 13(9): 807-813.

25. Hales CN, Barker DJP (1992) Type-2 (non-insulin dependent) diabetes mellitus: the thrifty phenotype hypothesis. Diabetologia 35(7): 595-601.

26. Wells JC (2007) The thrifty phenotype as an adaptive maternal effect. Biol Rev Camb Philos Soc 82(1): 143-172.

27. Roger Robinson (2001) The fetal origins of adult disease: No longer just a hypothesis and may be critically important in South Asia. BMJ 322(7283): 375-376.

28. Barker DJ (1992) The Fetal and infant origins of adult disease. BMJ Books London. 301(6761): 1111.

29. Veena SR, Geetha S, Leary SD, Saperia, Fisher DJ, et al. (2007) Relationship of maternal and paternal birth weights to features of the metabolic syndrome in the adult offspring: An integrational Study in South India. Diabetologia 50(1): 43-54. 
30. Kawai K, Spiegelman D, Shankar AH, Fawzi WW (2011) Maternal multiple micronutrient supplementation and pregnancy outcomes in developing countries: meta-analysis and meta-regression. Bull World Health Organ 89(6): 402-411.

31.Zefu TA, Ayele HT (2013) Micronutrients and pregnancy: the effect of supplementation on pregnancy and pregnancy outcome: a systematic review. Nutr J 12:20.

32. Yajnik CS, Fall CH, Coyaji KJ, Hirve SS, Rao S, et al. (2003) Neonatal anthropometry: the thin-fat Indian baby. The Pune Maternal Nutrition Study. Int J Obesity 27(2): 173-180.

33. Ferrante SC, Nadler EP, Pillai DK, Hubal MJ, Wang Z, et al. (2015) Adipocyte-derived exosomal miRNAs: A novel mechanism for obesityrelated disease. Pediatr Res 77(3): 447-454.

34. Wang TJ, Larson MG, Vasan RS, Cheng S, Rhee EP, et al. (2011) Metabolite profiles and risk of developing diabetes. Nat Med 17(4): 448-453.

35. Shinji Kume, Shin-ichi Araki, Nobukazu Ono, Atsuko Shinhara, Takahiko Muramatsu, et al. (2014) Predictive properties of plasma amino acid profile for cardiovascular disease in patients with type- 2 diabetes. PLoS One 9(6): 101219.

36. Chen T, Ni Y, Ma X, Bao Y, Liu J, et al. (2016) Branched-chain and aromatic amino acid profiles and diabetes risk in Chinese populations. Sci Rep 6: 20594.

37. Alison Gray (2015) Nutritional recommendations for individuals with diabetes. Endotext.

38. Evert AB, Boucher JL, Cypress M, Dunbar SA, Franz MJ, et al. (2013) Nutrition therapy recommendations for the management of adults with diabetes: Position statement by the ADA, Diabetes Care 36(11): 38213842 .

39. American Diabetes Association Standards of Medical Care-2017.The J Clin Appl Res \& Edu 40 (1): 1-132.
40. Sharma NR, Rao (2016) GHR: Diabetes management: Expectations and limitations. J Diab Metab 7: 662.

41. Volek JS, Phinney SD, Forsythe CE, Quann EE, Wood RJ, et al. (2009) Carbohydrate restriction has a more favorable impact on the metabolic syndrome than a low-fat diet. Lipids 44(4): 297-309.

42. Lean MEJ, Leslie WS, Barnes AC (2018) Primary care-led weight management for remission of type 2 diabetes (direct): an open -label, cluster-randomized trial. The Lancet 391 (10120): 541-551.

43. Abbasi J (2018) Interest in the ketogenic diet grows for weight loss and type-2 diabetes. JAMA 319(3): 215-217.

44. Puska P, Vartiainen E, Tuomilehto J, Nissinen A (1994) 20-year experience with the North Karelia Project. Preventive activities yield results. Nord Med 109(2): 54-55.

45. Puska P (2007) Health in all policies. Eur J Public Health 17:328.

46. Puska P (2008) The North Karelia Project: 30 years successfully preventing chronic diseases. Diabetes Voice 53.

47. Menotti A, Kromhout D, Blackburn H, Fidanza F, Buzina R, et al. (1999) Food intake patterns and 25-year mortality from coronary heart disease: cross-cultural correlations in the Seven Countries Study. The Seven Countries Study Research Group. Eur J Epidemiol 15 (6): 507-515.

48. Yusuf S, Hawken S, Ounpuu S, Dans T, Avezum A (2004) Effect of potentially modifiable risk factors associated with myocardial infraction in 52 countries (the INTERHEART study): Case-control study. Lancet 364(9438): 937-952.

49. Kromhout D, Menotti A, Bloemberg B, Aravanis C, Blackburn H, et al. (1995) Dietary saturated and trans fatty acids and cholesterol and 25year mortality from coronary heart disease: the Seven Countries Study. Prev Med 24(3): 308-315. 